\title{
Inverse Kinematics dan Pengukuran Akurasi Pergerakan pada Model Robot Manipulator Lengan
}

\author{
Achmad Zaki Rahman ${ }^{1, a)}$, Khairul Jauhari ${ }^{1, b)}$, Dede Sumantri ${ }^{2, c)}$, Tsani Hendro \\ Nugroho $^{3, \mathrm{~d})}$,Ilham Defra Nugraha ${ }^{1)}$, Sultan Amrullah ${ }^{4)}$ dan Haikal Ash Shabri ${ }^{4)}$ \\ ${ }^{1}$ Program Studi Teknik Mesin ITI, \\ Jl. Raya Puspiptek Serpong, Tangerang Selatan-Banten, Indonesia, 15320 \\ ${ }^{2}$ Laboratorium Teknik Produksi BT MEPPO-BPPT, \\ Gedung Teknologi 2 No. 251, Kawasan Puspiptek, Serpong, Tangerang Selatan-Banten, Indonesia, 15314
}

${ }^{3}$ Laboratorium Otomasi BT MEPPO-BPPT,

Gedung Teknologi 2 No. 251, Kawasan Puspiptek, Serpong, Tangerang Selatan-Banten, Indonesia, 15314

${ }^{4}$ Program Studi D3 Teknik Mesin UNY,

Jl. Colombo No.1, Karang Malang, Caturtunggal, Kec. Depok, Kabupaten Sleman, Daerah Istimewa Yogyakarta 55281

a)achmad.zakirahman@iti.ac.id (corresponding author), ${ }^{\text {b) }}$ khairul.jauhari@iti.ac.id, ${ }^{\text {c) }}$ dede.sumantri@bppt.go.id,

d) tsani.hendro@bppt.go.id,

\begin{abstract}
Abstrak
Memasuki era digital atau yang kini dikenal sebagai era Industri 4.0 ditandai dengan mulai berkembangnya teknologi robot pekerja yang mampu menggantikan manusia dalam melakukan aktivitas yang rutin dan berisiko tinggi. Jenis yang sangat populer menjadi robot pekerja adalah jenis robot manipulator lengan yang sering kita jumpai pada industri otomotif dan perakitan. Dalam penelitian ini berhasil dikembangkan sebuah manipulator lengan planar dengan jangkauan maksimum 23,5 cm sebagai media pembelajaran ilmu robotika. Manipulator ini menggunakan motor servo kecil dan digerakan oleh Raspberry Pi sebagai kontroler yang dapat di akses oleh programer melalui jaringan internet. Target koordinat end effector yang diberikan oleh programer robot diterjemahkan oleh software dengan perhitungan invers kinematik menjadi perintah gerakan putar untuk masing-masing motor servo pada setiap joint manipulator lengan. Dari 24 data pengujian yang telah dilakukan, rata-rata kesalahan dari sistem manipulator lengan yang telah dibuat ini adalah sebesar $5,7 \mathrm{~mm}$.
\end{abstract}

Kata kunci: robot industri, manipulator lengan, Industri 4.0, Raspberry Pi, invers kinematik

\begin{abstract}
Entering the digital era or what is now known as Industry 4.0 era is marked by the development of worker robot technology that is able to replace humans in carrying out routine and high-risk activities. A very popular type of robot worker arm robot manipulator that often encountered in the automotive and assembly line in industries. In this research, an arm robot manipulator had developed with its maximum range is $23.5 \mathrm{~cm}$ as an object for learning robotics. This manipulator use a small servo motors it driven by the Raspberry Pi as its controller that can be accessed by programmer via the internet network. The target end effector coordinates given by the robot programmer are translated by software with inverse kinematic calculations into rotary motion commands for each servo motor at manipulator arm joints. From 24 datas of measurement that have been done, the average error of the arm manipulator is $5.7 \mathrm{~mm}$.
\end{abstract}

Keywords: industrial robot, arm manipulator, Industry 4.0, Raspberry Pi, Inverse Kinematics.

\section{PENDAHULUAN}

Tantangan era digital saat ini dalam dunia industri saat ini semakin terasa. Dahulu, sering terlihat robot untuk proses pengecatan, dan pengelasan dalam aplikasi perakitan pada industri otomotif. Namun hari ini, dengan adanya kemajuan dalam teknologi kecerdasan buatan, elektronik, sensor, dan komputasi, penggunaan robot telah masuk ke dalam aplikasi baru dan ke industri lainnya. Seperti untuk menjalankan tugas militer, operasi di rumah sakit, ditempatkan di lingkungan berbahaya, dan pertanian.

Keberadaan robot pada hakikatnya adalah untuk menggantikan manusia, khususnya untuk melakukan pekerjaan yang berulang maupun pada area yang berbahaya bagi manusia [1]. Jenis robot yang paling banyak diaplikasikan pada dunia industri adalah robot lengan [2], atau bisa juga disebut sebagai manipulator lengan. Yaitu jenis robot manipulator yang berbentuk 
seperti lengan manusia dengan memiliki sendi yang disebut dengan joint dan komponen penghubung antar sendi yang disebut link [3]. Bentuk robot lengan ini mempunyai keunggulan fleksibilitas daerah kerja dalam dimensi ruang sehingga sangat cocok untuk diaplikasikan di berbagai proses industri. Untuk dapat menjalankan tugasnya, diperlukan suatu sistem perencanaan pergerakan manipulator dari kondisi awal sampai kondisi akhir sesuai dengan tugas yang telah diberikan [4].

Dalam tulisan ini akan dilakukan perhitungan inverse kinematika dari pergerakan manipulator lengan dalam mencapai suatu kordinat target. Pada Gambar 1 terlihat ilustrasi sistem manipulator lengan robot yang menggunakan Raspberry untuk mengontrol motor servo sebagai penggerak joint dari sistem lengan tersebut. Setelah manipulator bergerak sesuai perintah, maka akan dilakukan pengukuran akurasi dari pencapaian sistem manipulator lengan terhadap koordinat target yang diinginkan.

\section{LANDASAN TEORI}

\section{A. Inverse Kinematics Gerakan Manipulator}

Kinematika adalah ilmu mengenai geometri pergerakan alat atau benda yang meliputi gerak geometris murni melalui posisi, orientasi, dan turunan waktunya. Dalam robotika, ilmu kinematik digunakan untuk mengatur dan memperhitungkan dinamika sistem manipulator dalam mencapai target yang diinginkan [5].

Inverse kinematics atau kinematika terbalik adalah sebuah metoda untuk menghitung besarnya sudut-sudut pada joint manipulator lengan dalam rangka mencapai hasil yang diinginkan [2]. Karenanya terdapat beberapa cara untuk menyelesaikan permasalahan invers kinematika. Bahkan besaran sudut joint yang diperoleh bisa sangat beragam agar sistem manipulator dapat meraih target yang diharapkan.

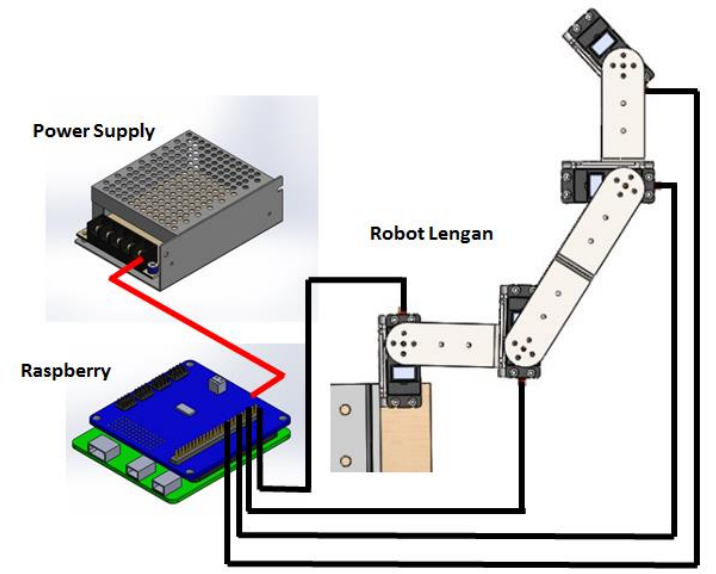

Gambar 1. Gambar Sistem Robot Lengan Planar 3 DOF

Sebagai contoh sistem yang dibangun pada penelitian ini akan menggunakan metoda geometrik untuk menentukan sudut-sudut joint lengan manipulator dalam rangka mencapai target yang dituju. Pada gambar 2 skema alat manipulator seolah-olah diletakan pada sebuah bidang (plane) koordinat x-y.

Bila koordinat target pada sumbu-X kita sebut $X$, dan koordinat pada sumbu-y adalah $\mathrm{Y}$, maka sudut $\theta_{0}$ yang akan terjadi ketika manipulator memperoleh koordinat target yang akan dicapai dapat diperoleh dengan cara:

$\theta_{0}=\operatorname{atan} 2(Y, X)$

Selanjutnya mencari nilai $-\mathrm{x}$ dan nilai-y yang merupakan ujung dari lengan kedua atau $l_{2}$

$x=X \cos \theta_{0}$

$y=Y \sin \theta_{0}$

Bila diketahui:

$x=l_{1} \cos \theta_{1}+l_{2} \cos \left(\theta_{1}+\theta_{2}\right)$

$y=l_{1} \sin \theta_{1}+l_{2} \sin \left(\theta_{1}+\theta_{2}\right)$

Maka bila kita persamaan (4) dan (5) masing-masing dikuadratkan dan dijumlahkan akan menjadi:

$$
\begin{aligned}
x^{2}+y^{2}= & l_{1}^{2} \cos ^{2} \theta_{1}+l_{2}^{2} \cos ^{2}\left(\theta_{1}+\theta_{2}\right)+ \\
& 2 l_{1} l_{2} \cos \theta_{1} \cos \left(\theta_{1}+\theta_{2}\right)+l_{1}^{2} \sin ^{2} \theta_{1}+ \\
& l_{2}^{2} \sin ^{2}\left(\theta_{1}+\theta_{2}\right)+2 l_{1} l_{2} \sin \theta_{1} \sin \left(\theta_{1}+\theta_{2}\right)
\end{aligned}
$$

kemudian bila disederhanakan, persamaannya akan menjadi [2]:

$$
\begin{aligned}
& x^{2}+y^{2}=l_{1}^{2}+l_{2}^{2}+2 l_{1} l_{2} \cos \theta_{2} \\
& \cos \theta_{2}=\frac{x^{2}+y^{2}-l_{1}^{2}-l_{2}^{2}}{2 l_{1} l_{2}} \\
& \sin \theta_{2}= \pm \sqrt{1-\cos ^{2} \theta_{2}}
\end{aligned}
$$

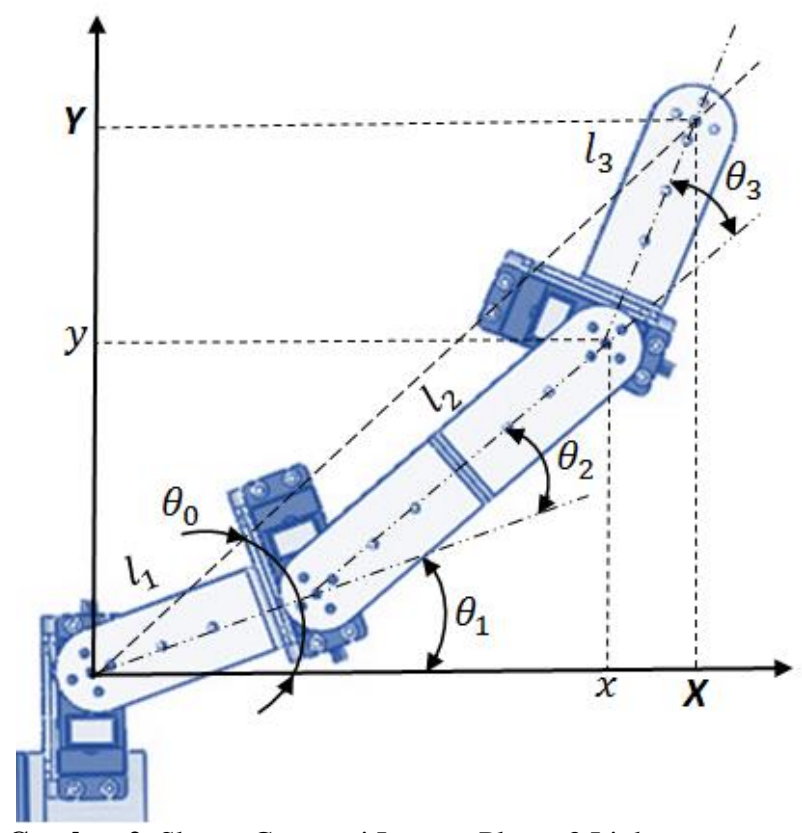

Gambar 2. Skema Geometri Lengan Planar 3 Link

maka besarnya $\theta_{2}$ adalah:

$\theta_{2}=\operatorname{Atan} 2\left(\sin \theta_{2}, \cos \theta_{2}\right)$

Setelah diperoleh $\theta_{2}$, maka bentuk persamaan (4) dan (5) dapat digunakan untuk mencari $\theta_{1}$ dengan bentuk [3]: 
$x=k_{1} \cos \theta_{1}-k_{2} \sin \theta_{1}$

$y=k_{1} \sin \theta_{1}+k_{2} \cos \theta_{1}$

dimana

$k_{1}=l_{1}+l_{2} \cos \theta_{2}$

$k_{2}=l_{2} \sin \theta_{2}$

Agar $\theta_{1}$ dapat diketahui, maka variabel persamaan diubah menjadi [2]:

$r=\sqrt{k_{1}^{2}+k_{2}^{2}}$

$\gamma=\operatorname{Atan} 2\left(k_{2}, k_{1}\right)$

kemudian:

$k_{1}=r \cos \gamma$

$k_{2}=r \sin \gamma$

sehingga persamaan (10) dan (11) dapat ditulis menjadi:

$\frac{x}{r}=\cos \gamma \cos \theta_{1}-\sin \gamma \sin \theta_{1}$

$\frac{y}{r}=\cos \gamma \cos \theta_{1}+\sin \gamma \sin \theta_{1}$

maka:

$\cos \left(\gamma+\theta_{1}\right)=\frac{x}{r}$

$\sin \left(\gamma+\theta_{1}\right)=\frac{y}{r}$

dari dua persamaan di atas, diperoleh

$\gamma+\theta_{1}=\operatorname{Atan} 2\left(\frac{y}{r}, \frac{x}{r}\right)=\operatorname{Atan} 2(y, x)$

dan diperolehlah:

$\theta_{1}=\operatorname{Atan} 2(y, x)-\operatorname{Atan} 2\left(k_{2}, k_{1}\right)$

Terakhir, untuk $\theta_{3}$ :

$\theta_{3}=\theta_{0}-\theta_{1}-\theta_{3}$

Dalam inverse kinematik terdapat banyak ragam pilihan penyelesaian bagi manipulator lengan dalam mencapai koordinat target yang diinginkan [2]. Solusi tersebut sangat tergantung pada banyak variabel, seperti spesifikasi komponen, lintasan kerja manipulator, beban dinamis, dan sebagainya. Sebagai ilustrasi dapat dilihat pada Gambar 3, yang memperlihatkan manipulator harus mengambil lintasan lain ketika ingin berpindah dari titik A ke titik B dikarenakan ada penghalang (obstacle).

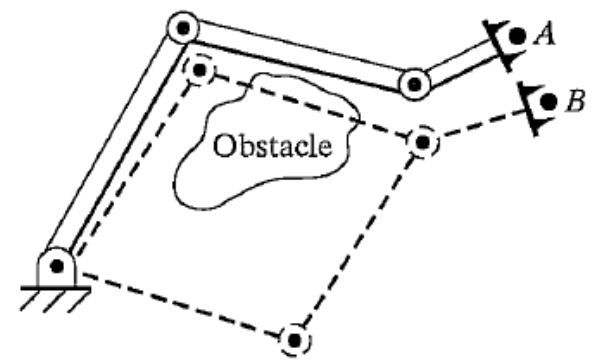

Gambar 3. Lintasan Lain Untuk ke Titik B Untuk Menghindari Obstacle. [2]

\section{B. Controller}

Raspberry adalah fisical computer yang memiliki input ouput (I/O) untuk berinterakasi dengan sejumlah device dan aktuator. Dengan adanya (I/O), raspberry merupakan gabungan antara komputer dengan microcontroller yang beroperasi pada sistem operasi linux sebagaimana dapat dilihat pada Gambar 4.

Raspberry Pi memiliki dua model: model A dan model B. Secara umum Raspberry Pi Model B memiliki kapasitas penyimpanan RAM sebesar $512 \mathrm{MB}$. Perbedaan model A dan B terletak pada modul penyimpanan yang digunakan. Model A menggunakan penyimpanan sebesar $256 \mathrm{MB}$ dan penyimpanan model B sebesar 512 MB. Selain itu, model B sudah dilengkapi dengan porta Ethernet (untuk LAN) yang tidak terdapat di model A. Desain Raspberry Pi didasarkan pada SoC (system-on-a-chip) Broadcom BCM2835, yang telah menanamkan prosesor ARM1176JZF-S dengan $700 \mathrm{MHz}$, GPU VideoCore IV, dan RAM sebesar $256 \mathrm{MB}$ (model B). Penyimpanan data tidak didesain untuk menggunakan cakram keras atau solid-state drive, melainkan mengandalkan kartu penyimpanan tipe SD untuk menjalankan sistem dan sebagai media penyimpanan.

Pemilihan Raspberry $P i$ sebagai kontroller pada penelitian ini ditujukan agar programer dapat mengontrol robot manipulator melalui jaringan yang tersedia. Hal ini sebagai awalan dalam penerapan teknologi Internet of Things (IOT) pada sistem robot yang dibangun.

\section{METODA PENELITIAN}

Penelitian ini menggunakan manipulator lengan planar dengan 3 joint yang menggunakan tiga motor servo dan Raspberry pi-3 sebagai controller-nya. Sedang sebagai link-nya menggunakan bracket standar dari motor servo yang digunakan seperti pada Gambar 5.

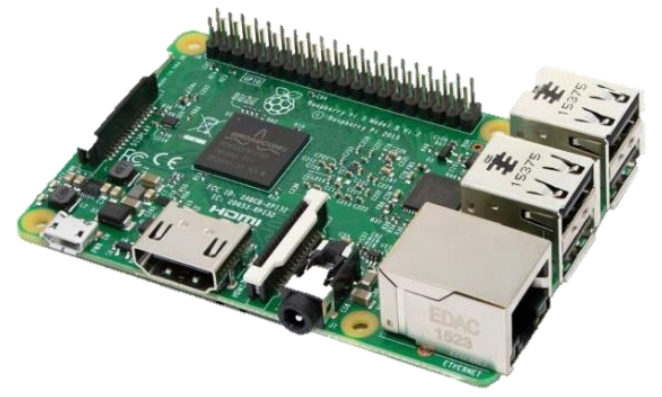

Gambar 4. Raspberry Pi-3 yang Dilengkapi Port LAN

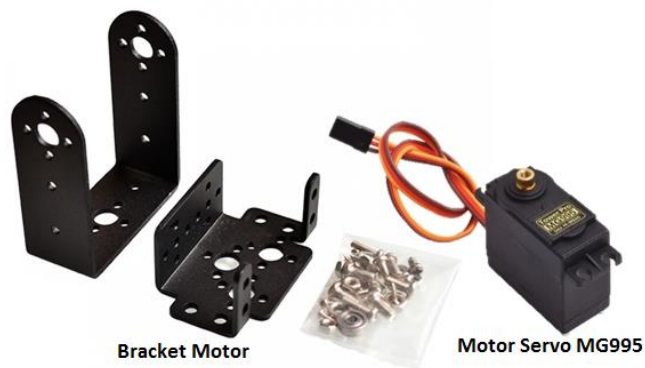

Gambar 5. Bracket dan Motor Servo 
Sistem manipulator lengan secara keseluruhan dirakit seperti pada Gambar 1. Sedangkan untuk melakukan pengukuran menggunakan kertas milimeter blok yang dipasang pada bagian bawah manipulator seperti yang terlihat pada Gambar 6 .

Panjang lengan 1 atau $l_{1}$ seperti pada Gambar 2 adalah sama dengan lengan ketiga yang di ujung (end effector) atau $l_{3}$ yaitu $6,5 \mathrm{~cm}$. Sedangkan untuk lengan kedua atau $l_{2}$ yang berada di tengah manipulator adalah $10,5 \mathrm{~cm}$. Sehingga panjang jangkauan maksimal manipulator adalah :

$$
l_{1}+l_{2}+l_{3}=6,5+10,5+6,5=23,5 \mathrm{~cm}
$$

Sehingga diputuskan untuk koordinat tujuan yang akan diambil nilai $x$ dan $y$-nya di dalam rentang $0-23 \mathrm{~cm}$. Kemudian untuk langkah-langkah perhitungan dan pengukuran dapat dilihat pada Gambar 7.

Namun tidak semua hasil perhitungan sudut joint dapat langsung digunakan untuk menggerakkan manipulator, karena motor servo yang digunakan memiliki rentang gerak putar dari $0^{\circ}-180^{\circ}$ saja. Untuk itu perlu dilakukan perhitungan ulang bila terdapat sudut yang nilainya diluar kemampuan motor seperti yang terlihat pada Gambar 6 .

Kemudian, software yang dibuat secara otomatis membulatkan nilai sudut yang diperoleh dari hasil perhitungan invers kinematik pada setiap joint agar memudahkan pengecekan yang dilakukan dengan busur derajat. Akibatnya akan terjadi selisih nilai antara sudut awal perhitungan dengan nilai sudut akhir setelah dibulatkan, atau yang biasa kita kenal dengan error pembulatan. Hal inilah yang menyebabkan koordinat target hasil perhitungan menjadi sedikit berbeda dengan target awal yang ingin dicapai. Koordinat inilah yang pada flow chart di Gambar 7 disebut sebagai $X_{1}$ dan $Y_{1}$. Sehingga untuk mengetahui keakurasian manipulator, maka koordinat hasil pengukuran gerakan end effector dibandingkan dengan koordinat hasil perhitungan yang telah dilakukan oleh software. Koordinat riil yang berhasil dicapai oleh end effector selanjutnya disebut sebagai $X_{2}$ dan $Y_{2}$.

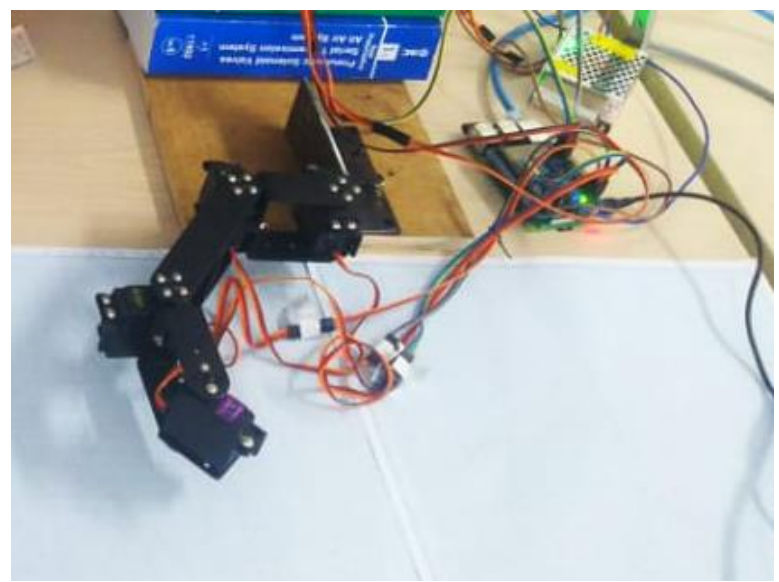

Gambar 6. Pengukuran Gerakan Manipulator Dengan Kertas Milimeter Blok
Perhitungan error atau selisih antara koordinat $\left(X_{1}, Y_{1}\right)$ dan $\left(X_{2}, Y_{2}\right)$ menggunakan rumus jarak dua titik seperti di bawah ini:

$R=\sqrt{\Delta x^{2}+\Delta y^{2}}$

di mana $\Delta x=X_{1}-X_{2}$ dan $\Delta y=Y_{1}-Y_{2}$

\section{HASIL PERCOBAAN DAN PEMBAHASAN}

Hasil dari perhitungan dan pengukuran dari penelitian ini dapat dilihat pada Tabel 1. Di mana terdiri dari 24 varian percobaan yang dapat dilihat pada kolom "Target". Varian target tersebut, masing-masing dihitung invers kinematiknya dan hasilnya dapat dilihat pada kolom "Perhitungan". Hasil perhitungan tersebut dijadikan perintah bagi manipulator lengan untuk mencapai titik tersebut $\left(X_{1}, Y_{1}\right)$. Kemudian manipulator bergerak, titik koordinat pada end effector diukur $\left(X_{2}, Y_{2}\right)$ dan ditampilkan pada Tabel 1 kolom "Pengukuran".

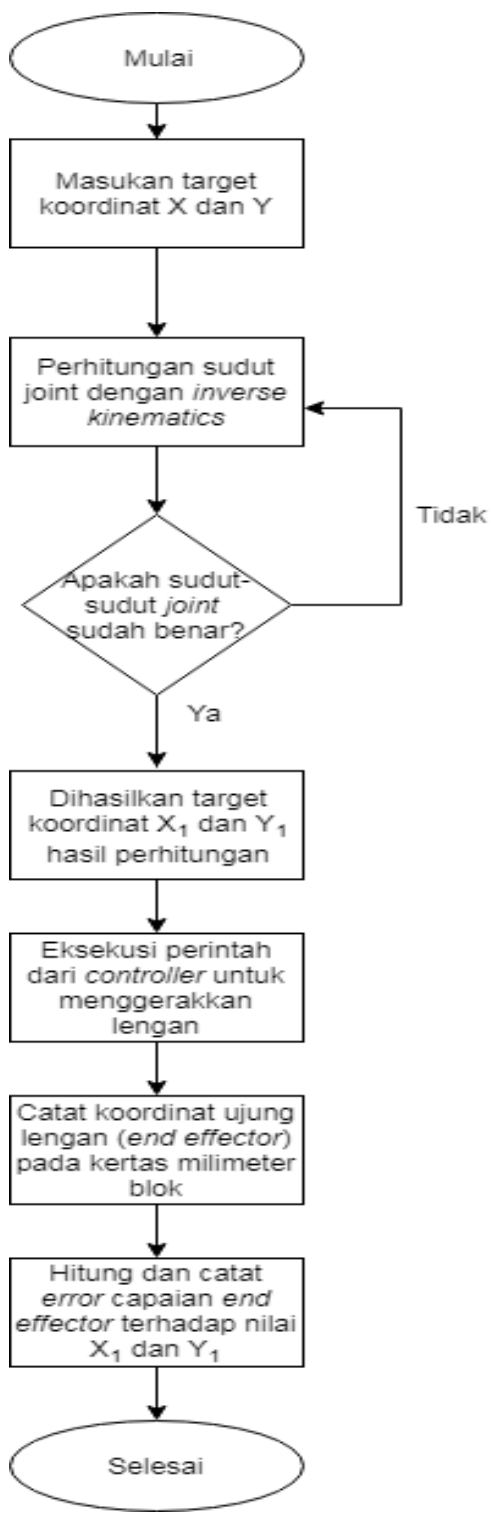

Gambar 7. Flowchart Proses Perhitungan dan Pengukuran Manipulator Lengan 
Pada Gambar 8 dapat dilihat gap yang terjadi dari hasil penelitian ini, yaitu antara target awal, koordinat perhitungan dan hasil pengukuran. Sedangkan untuk visualisasi pergerakan manipulator lengan hasil perhitungan invers kinematik pada masing-masing target dapat dilihat pada Gambar 9. Dari gambar tersebut dapat dilihat koordinat dari masing-masing joint dan sudut link yang terbentuk untuk mencapai koordinat yang diinginkan $\left(X_{1}, Y_{1}\right)$.

Tabel 1.Tabel Hasil Pengukuran

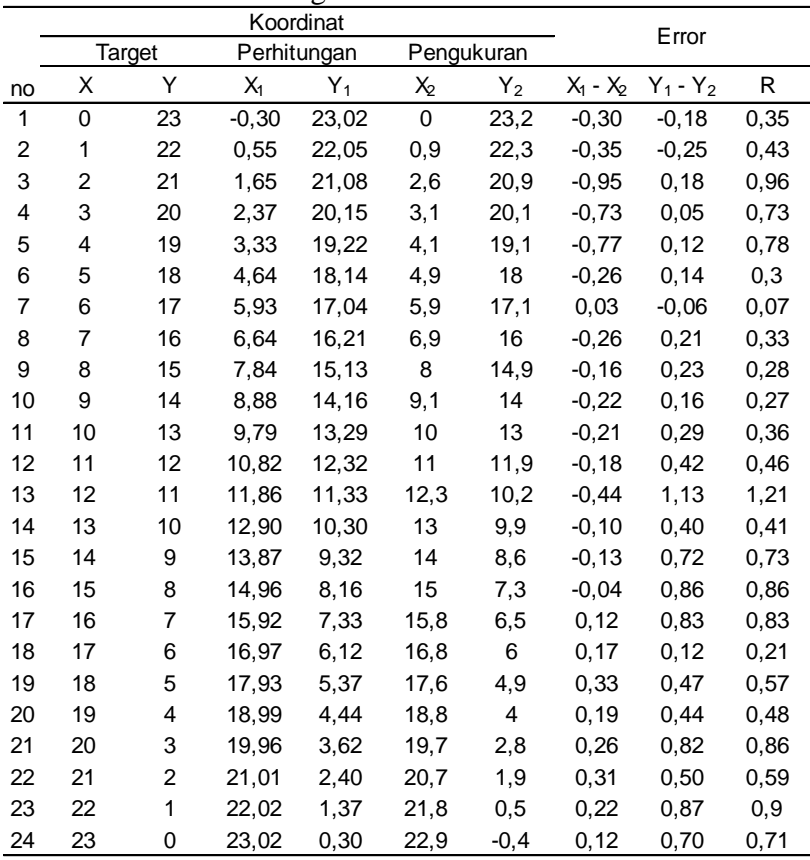

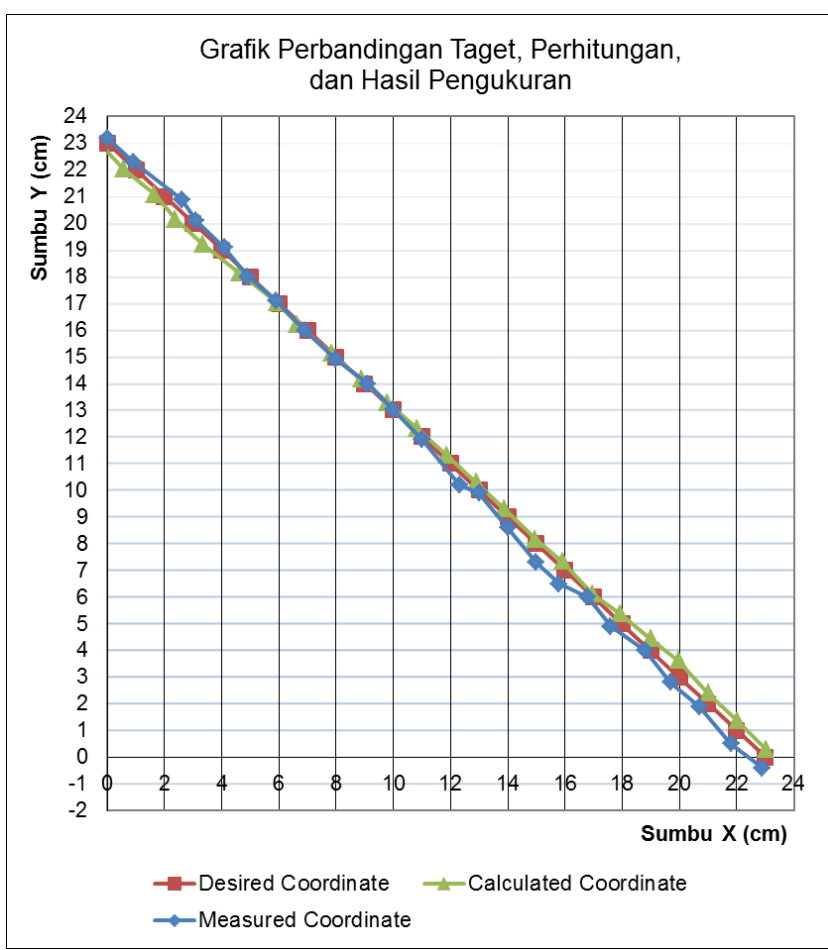

Gambar 8. Grafik Hasil Perbandingan Koordinat Target $(X, Y)$, Perhitungan $\left(X_{1}, Y_{1}\right)$ dan Pengukuran $\left(X_{2}, Y_{2}\right)$

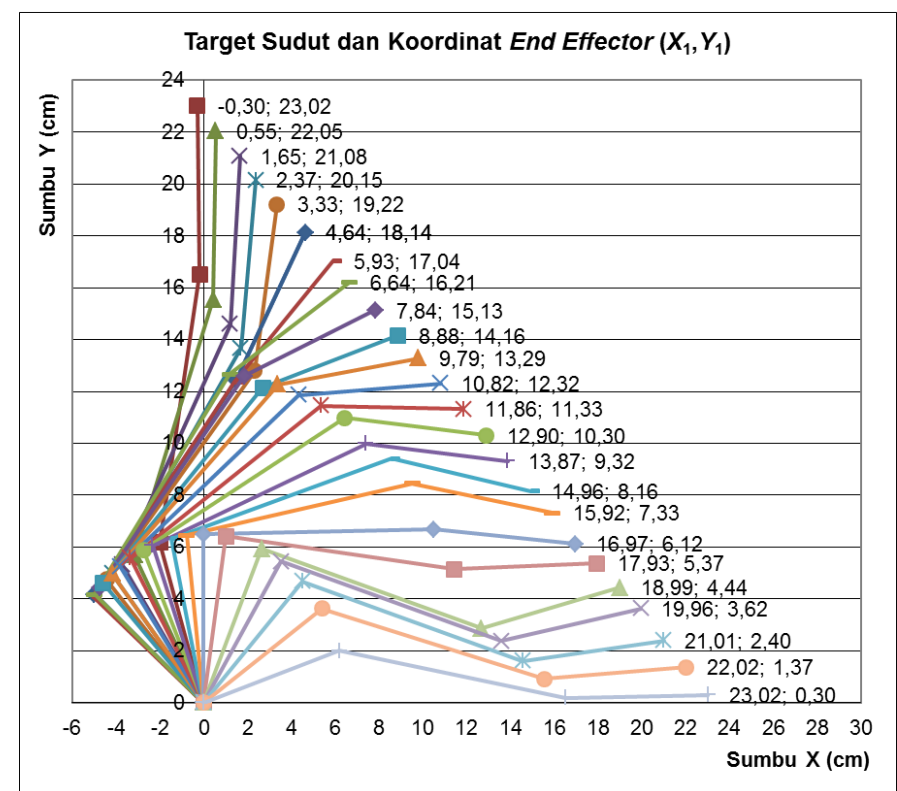

Gambar 9. Simulasi Pergerakan Manipulator Dalam Mencapai Target Perhitungan $\left(X_{1}, Y_{1}\right)$

\section{KESIMPULAN}

Dari hasil penelitian ini dapat disimpulkan bahwa:

1. Telah dihasilkan sebuah robot planar jenis manipulator lengan dengan menggunakan controller Raspberry Pi.

2. Dengan menggunakan invers kinematik, manipulator lengan berhasil mencapai koordinat yang dituju.

3. Kesalahan atau error rata-rata yang terjadi adalah sebesar 5,7 $\mathrm{mm}$. Dengan error terkeil pada data nomor 7 yaitu sebesar $0,7 \mathrm{~mm}$ dan yang terbesar adalah pada data nomor 3 yaitu 9,6 mm.

4. Kesalahan terjadi akibat adanya pembulatan nilai sudut (round error) pada controller ketika memberikan perintah kepada motor servo untuk berputar. Ditambah lagi dengan adanya backlash dari sistem manipulator lengan mengakibat terjadinya penambahan error (cumulative error) pada end effector.

\section{UCAPAN TERIMA KASIH}

Ucapan terimakasih kami berikan kepada berbagai pihak yang turut mendukung dan berkontribusi pada penelitian ini. Khususnya kepada Kemenristekdikti yang mendanai penelitian ini melalui hibah Penelitian Dosen Pemula (PDP) tahun 2019 dengan nomor kontrak 225/SP2H/LT/DPRM/2019, tanggal: 11 Maret 2019.

\section{REFERENSI}

[1] R. Gautam, A. Gedam, A. Zade, A.Ajay Mahawadiwar, Review on Development of Industrial Robotic Arm, International Research Journal of Engineering and Technology (IRJET), Volume: 04 Issue: 03, Maret 2017.

[2] J. J. Craig, Introduction to Robotics: Mechanics and Control,Pearson Education, Inc., 2008.

[3] R. Oktama, R Maulana, G. E. Setyawan. Implementasi Robot Lengan Pemindah Barang 3 DOF Menggunakan Metoda Inverse Kinematics. Jurnal Pengembangan 
Teknologi Informasi dan Ilmu Komputer, Vol.2, no. 8, Agustus 2018, hlm. 2810-2816.

[4] M. I. Afandi, Simulasi Pergerakan Trajectory Planning pada Robot Lengan Anthropomorphic. Amteq. 2006

[5] R.N. Jazar. Theory of Applied Robotics, 2nd edition, Springer, 2010. 